Available online at_www.iponlinejournal.com

\title{
Study of asphyxial death due to pressure over the neck with special reference to hyoid bone fracture, gross and radiological observations
}

\author{
Vijaykumar Kaushik $^{1 *}$, Mohammed Iliyas Sheikh², Reena V. Kaushik ${ }^{3}$ \\ ${ }^{1}$ Tutor, ${ }^{2}$ Professor and HOD, ${ }^{3}$ Tutor, ${ }^{1}$ Dept. of Forensic Medicine \& Toxicology, ${ }^{2}$ Dept. of Physiology, Surat Municipal \\ Institute of Medical Education and Research, Surat, Gujarat, India
}

\begin{abstract}
Aims of the study was to observe the pattern of injuries in asphyxial death on gross and radiological examination. Evidence of extravasations of blood around the fracture site was accepted as antemortem in presence of other injuries to neck like bruises and soft tissue haemorrhage. Therefore, gross \& radiological examination of the hyoid bone is to decide the actual manner of death.
\end{abstract}

Keywords: Hanging, Strangulation, Hyoid bone, Thyroid cartilage, Radiological examination.

\section{Introduction}

Asphyxia may result from a number of varied circumstances. It may arise from breathing air that is low in oxygen, from compression of the external airways (nose and mouth), from obstruction of the internal airways, from external compression of the neck or chest, or from awkward positioning of the body. "Chemical" asphyxia has been attributed to toxins such as carbon monoxide and cyanide that act on the molecular and cellular level by hindering the delivery of oxygen to the tissues. ${ }^{1}$ Asphyxia means apparent or actual cessation of life due to interruption of effective gaseous exchange in the lungs. ${ }^{2}$

Death is certain for all living beings but only human end their lives prematurely by committing suicide. Among various methods opted, hanging is one of the most common method. In today's world, crime and violence has a great proportion of human lives. In spite of advancing civilization, killing self or someone is so easy in these days. Hanging is in practice from the time immemorial and before advent of civilization. In ancient Rome, death by suicidal hanging was regarded as particularly shameful and those who had died by this method were refused a burial. Among the asphyxial deaths mentioned above hanging is the commonly used method of committing suicide and strangulation is the commonly used method for homicidal purpose. ${ }^{3}$

Hanging is a form of asphyxia death due constriction of the air passage at the neck as a result suspension of the body by a ligature in the form of noose, applied in such a manner, when weight of the body (complete hanging), or other part of the body eg. head acts as constricting force (partial hanging). Deaths resulting from hanging show features amongst which the ligature mark in the neck is considered to be decisive. Hanging deaths are suicidal, accidental and rarely homicidal in nature. ${ }^{4}$

An additional asphyxiating factor found in cases of hanging and strangulation is obstruction of the laryngeal inlet by upward displacement of the tongue and pharynx caused by the constricting force around the neck. (The autopsy diagnosis of death due to fatal compression of neck is extremely difficult and sometimes goes unnoticed if the ligature mark is faint or invisible.) It is easy to diagnose hanging when one finds the classical features. However all features are seldom present together. The classical signs of asphyxia are nonspecific and can occur in deaths from other causes.

\footnotetext{
*Corresponding Author: Vijaykumar Kaushik, Dept. of Forensic Medicine \& Toxicology, Surat Municipal Institute of Medical Education and Research, Surat, Gujarat, India

Email: vijay.kaushik62@gmail.com

http://doi.org/10.18231/j.ijfmts.2019.019
} 
Whether the hanging is ante mortem or postmortem, absence of tissue reaction to ligature and lack of congestive changes may not be taken as an evidence that the body was hanged after death. Circumstances in which body was found may be of much help. A detailed autopsy supported by necessary laboratory investigation may be quite rewarding. ${ }^{5}$

In ligature strangulation, injuries to deeper tissues of neck are more common than hanging, as a result of considerable force which is used. The superior horns of the thyroid cartilage are commonly fractured but the hyoid is rarely fractured, due to the level of constriction being below this bone, unless considerable violence is applied to neck. ${ }^{6,7}$

The ligature force up the epiglottis and the root of tongue against the posterior wall of the pharynx and the floor of the mouth is jammed against its roof, and occludes the air passage, also the uvula and soft palate are pushed upwards and the laryngeal opening is blocked by the depressed epiglottis. ${ }^{8}$

Ante mortem fracture of hyoid bone is diagnosed by gross examination and radiological examination. ${ }^{9}$ On gross examination, evidence of haemorrhage around the fracture site suggesting ante-mortem phenomena associated with other injuries to neck like bruises and soft tissue haemorrhage. ${ }^{10,11}$

\section{Materials and Methods}

Present study was carried out on the unnatural asphyxial death with neck compression those were brought for medico legal post mortem examination at tertiary care centre. Detailed performa was prepared; information had been collected from police records, available hospital records, circumstances of death and interrogation with investigating officer and relatives of the deceased. Standard autopsy protocol was followed with proper observation of cadaver externally and internally. The examination of ligature mark with reference of ligature material (if present) was performed and the position of knot was examined \& correlated.

Bloodless dissection of the neck was carried out by removing thoraco-abdominal and the cranial contents. Layer wise dissection was carried from the lower border of lower jaw, laterally on both sides of neck and clavicle below. Deep cervical fascia is reflected from cervical muscles and strap muscles of the neck, and exposed, inspected and reflected on each side followed by palpation of the hyoid bone and thyroid cartilage for fractures with bleeding in situ and also looked for muscles haemorrhage, rupture and intimal tear of carotid arteries. The throat skeleton as a single mass was removed for detailed dissection and radiological examination. Prevertebral fascia and the paraspinal muscles were removed and cervical vertebrae were looked and palpated for fracture with haemorrhage.

\section{Observations and analysis}

Present study was carried out on 100 cases of fatal neck compression brought for medicolegal post mortem examination during the period 2014- 2015 at tertiary referral care center of Surat. Hanging constitutes 95(95\%), Strangulation constitutes 05 (5\%) and Throttling constitutes $0(0 \%)$.

Among 100 cases of fatal neck compression, 69 were male and 31 were female, with a male to female ratio of 2.22:1. This is shown in Table 1

Majority of victims belong to age group 21 to 30 (37 cases), followed by 31 to 40(24 cases) and 11 to 20(18 cases). This is shown in Table 2

The most frequent level of the ligature mark was observed over the neck in our study was above the thyroid cartilage in 83 cases. At the mandible base and over the thyroid cartilage accounts for 7 cases each and in 3 cases it was present below the thyroid cartilage. This is shown in Table 3

In the present study, on gross examination fracture of hyoid bone was found on right side in 11 cases and on left side in 5 cases. It was absent in 84 cases. On Xray examination hyoid bone fracture was present in right side in 11 cases and on left side in 5 cases. It was absent in 84 cases. In 2 cases fracture of hyoid bone was found in female due to strangulation and in 2 cases fracture of hyoid bone was found in male as a result of strangulation. This is shown in Table 4

Out of the 100 cases studied, hyoid bone fracture was found in 16 cases ( 13 cases were male and 3 cases were female) and thyroid cartilage fracture was found in 4 cases ( 3 cases were male and 1 cases were female),in 1 case both hyoid \& thyroid were fractured 
and rest of the cases does not show any fracture. This is shown in Table 6 and Graph No.1.
In the present study, in $95 \%$ of the cases manner of death was suicidal, in $5 \%$ it was homicidal and no accidental death was found. This is shown in Table 6

Table 1: Sex wise distribution of victims of asphyxial death

\begin{tabular}{|c|c|c|}
\hline Sex & No. of cases & Percentage \\
\hline Male & 69 & $69 \%$ \\
\hline Female & 31 & $31 \%$ \\
\hline Total & 100 & $100 \%$ \\
\hline
\end{tabular}

Table 2: Age wise distribution of victims of asphyxia death

\begin{tabular}{|c|c|c|c|c|c|c|c|c|}
\hline Age group in yrs. & $<\mathbf{1 0}$ & $\mathbf{1 1 - 2 0}$ & $\mathbf{2 1 - 3 0}$ & $\mathbf{3 1 - 4 0}$ & $\mathbf{4 1 - 5 0}$ & $\mathbf{5 1 - 6 0}$ & $\mathbf{6 1 - 7 0}$ & $\mathbf{7 1 - 8 0}$ \\
\hline Frequency & 1 & 18 & 37 & 24 & 14 & 3 & 2 & 1 \\
\hline Male & 1 & 11 & 26 & 16 & 12 & 3 & 1 & 1 \\
\hline Female & 0 & 7 & 11 & 8 & 2 & 0 & 1 & 0 \\
\hline
\end{tabular}

Table 3: According to level of ligature mark

\begin{tabular}{|l|c|c|}
\hline \multicolumn{1}{|c|}{ Level of ligature mark } & Frequency & Percent \\
\hline At the mandible base & 7 & $7 \%$ \\
\hline Above the thyroid cartilage & 83 & $83 \%$ \\
\hline Over the thyroid cartilage & 7 & $7 \%$ \\
\hline Below the thyroid cartilage & 3 & $3 \%$ \\
\hline Total & 100 & $100 \%$ \\
\hline
\end{tabular}

Table 4: According to fracture of Hyoid bone

\begin{tabular}{|l|c|c|}
\hline \multicolumn{1}{|c|}{ Fracture of hyoid bone } & No. of cases & Percent \\
\hline On gross examination & & \\
\hline A) Present & & $11 \%$ \\
\hline i) Right side & 5 & $5 \%$ \\
\hline ii) Left side & 84 & $84 \%$ \\
\hline B) Absent in & & \\
\hline On X ray examination & & \\
\hline A) Present in & 11 & $11 \%$ \\
\hline i) Right side & 5 & $5 \%$ \\
\hline ii) Left side & 84 & $84 \%$ \\
\hline B) Absent in & & \\
\hline
\end{tabular}

Table 5: According to neck structure fracture

\begin{tabular}{|c|c|c|c|}
\hline Neck structure & Frequency & Total no. Of cases & Percent \\
\hline Hyoid & $16(13 \mathrm{M}, 3 \mathrm{~F})$ & 100 & $16 \%$ \\
\hline Thyroid cartilage & $4,0(3 \mathrm{M}, 1 \mathrm{~F})$ & 100 & $4 \%$ \\
\hline Both & $1(\mathrm{M})$ & 100 & $1 \%$ \\
\hline
\end{tabular}


Table 6: According to manner of death

\begin{tabular}{|c|c|c|}
\hline Manner of death & Present & Percent \\
\hline Homicidal & 05 & $5 \%$ \\
\hline Suicidal & 95 & $95 \%$ \\
\hline Accidental & 0 & $0 \%$ \\
\hline Total & 100 & $100 \%$ \\
\hline
\end{tabular}

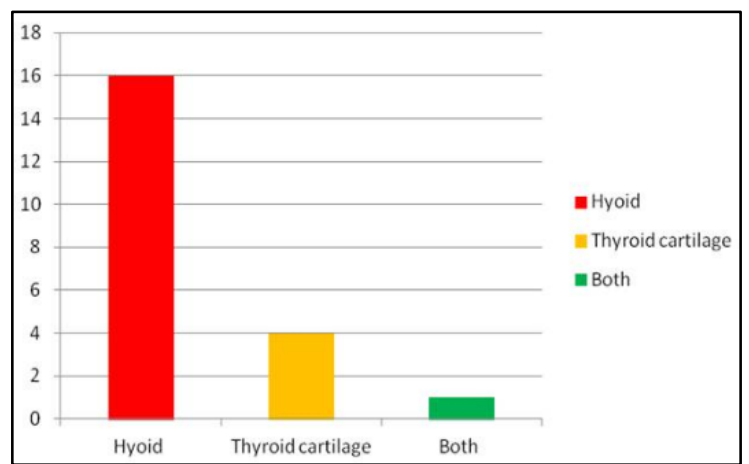

Fig. 1: According to neck Structure

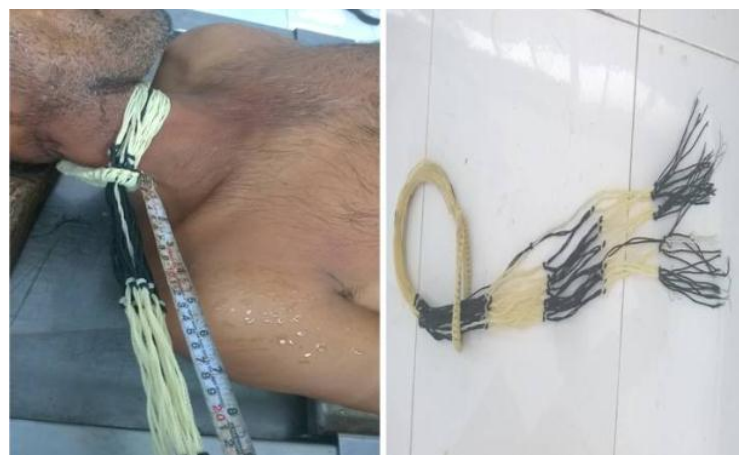

Fig. 2: Ligature material at situ and has been removed and correlated with ligature mark

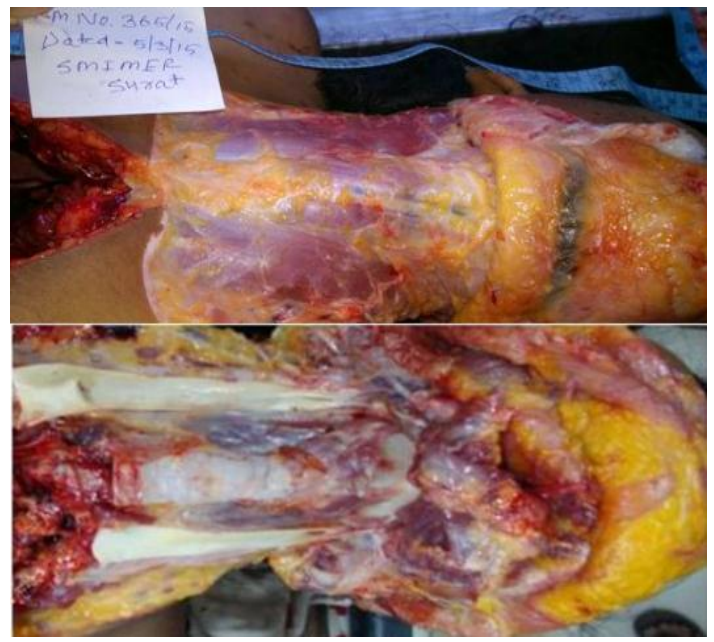

Fig. 3: Thoraco-abdominal contents are removed before the neck dissection \& Layer wise bloodless dissection and carotid artery dissection.

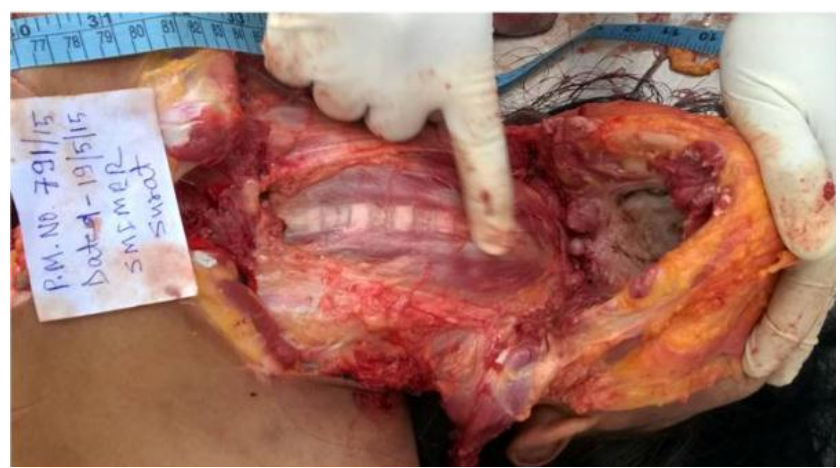

Fig. 4: Looking for any crepitation and abnormal mobility of spine.

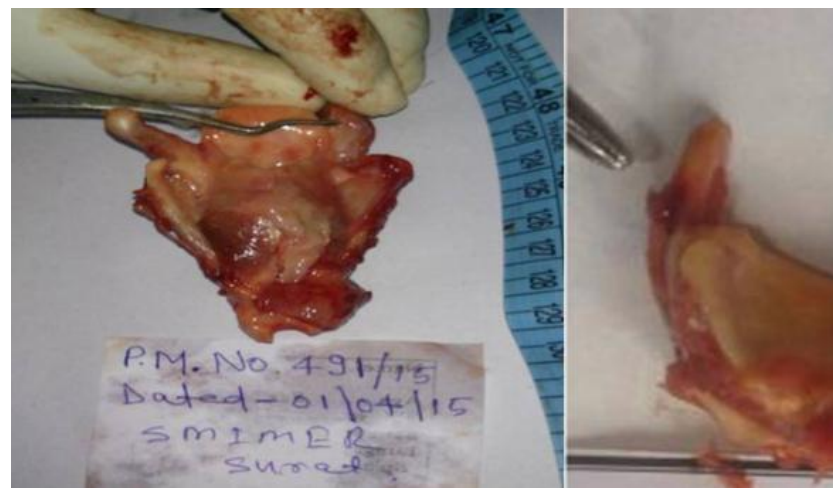

Fig. 5: Outward (right) and inward (left) compression fracture of hyoid with haemorrhage.

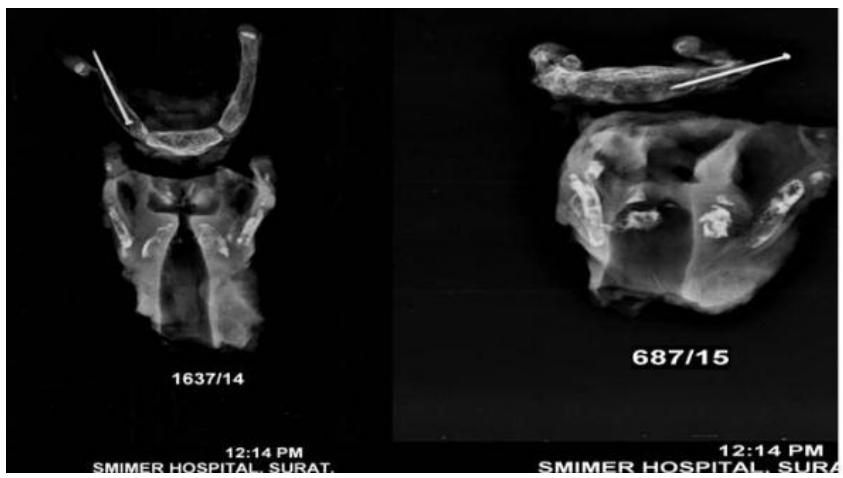

Fig. 6: Outward (left) and inward (right) compression fracture of hyoid bone in $\mathrm{x}$-ray. 


\section{Discussion}

Violence in any form is intolerable and unacceptable in the society. But the incidents of violence in both forms; killing self or someone are recorded since the existence of human being for one or the other reason. In today's world, violence against humans is increasing. In spite of progressing civilization and improvement of living standards in our society, the violence rate has not come down. Though the mortality rate is controlled by advancement in the technology, it is quite evident that there is definite increase in unnatural deaths due to accidents, suicides and even homicides.

The present study showed a wide range of similarities and dissimilarities in finding and mode of asphyxial death with the works of other authors. Out of 100 cases of asphyxial deaths were examined, 95\% of hanging and 5\% of strangulation. The youngest victim in present study was 4 year male and the eldest was 82 year male. Majority of the cases $37(37 \%)$ fall in to the age group 21 to 30 years, followed by 31 to 40 years $24(24 \%) ; 11$ to 20 years $18(18 \%) ; 41$ to 50 years 14(14\%); 51-60 years 3(3\%); Less than 10 years and seventh decade incidence came down to 1 case $(1 \%)$; and one case (1\%) is in eighth decade.

Though many authors claim that hyoid bone fracture increases with increasing age above 40 years Out of the 100 cases studied, hyoid fracture was found in 16 cases, 13 cases were male and 3 cases were female, 13 cases in hanging and 3 cases in ligature strangulation. The other neck structures like cricoid cartilage and cervical spine did not show any fracture. Similar findings were observed in the studies conducted by Ahmad M, Hossain M Z; ${ }^{12}$ Sheikh M M $\mathrm{M}$ et $\mathrm{al}^{13}$; Charoonnate $\mathrm{N}$ et al. ${ }^{14}$ It is in contrast to the findings observed by Feigin $\mathrm{G} ;{ }^{15}$ Sharma BR et al $;{ }^{16}$ Green $\mathrm{H}$ et $\mathrm{al}^{17}$ in which thyroid cartilage fracture was more common than hyoid bone fracture.

All the cases were violent asphyxia death due to pressure over neck, similar to studies by Momin SG et al $;{ }^{18}$ Naik S S Ket al $;{ }^{19}$ Chandrakant MK et al $;{ }^{20}$ Saisaudheer $\mathrm{T}$ et $\mathrm{al} ;{ }^{21}$ Rajs $\mathrm{J}$, Thiblin Iet $\mathrm{al}^{22}$ It indicates that incidence of hanging more as compare to strangulation.

\section{Conclusion}

1. The present study showed a wide range of similarities and dissimilarities in finding and mode of asphyxial death with the works of other authors. It indicates that incidence of hanging more as compare to strangulation. It can be concluded that presence of other bodily injuries suggest only manner of death not about hanging or ligature strangulation. In suspicious cases final opinion was made depending upon circumstantial evidence and gross autopsy \& radiological findings. Doubtful fracture on gross examination followed by soft tissue X-ray will help in decision making for ante mortem fracture.

2. Visiting the scene of crime or at least having a look at the photograph of scene of occurrence should include point of suspension is useful to determine the manner of death.

3. There should be a protocol for examination of fatal neck compression cases - which consists of bloodless dissection, palpation before en masse removal, en masse removal of neck skeleton, separating the individual skeleton for detailed examination

4. Increasing incidence of hyoid bone fracture after the age of 40 years can be concluded only after taking larger numbers of such cases, which need further continuous study in this regard.

\section{Source of Funding}

None.

\section{Conflict of Interest}

None.

\section{References}

1. Vincent j. Dinio Dominick Diamai, forensic pathology, Asphyxia $2^{\text {nd }}$ edition, CRC, press, Washington 2001,P 2001:229-32.

2. Dorland's medical dictionary $24^{\text {th }}$ edition, oxford $\&$ IBH publication, New Dehli,65.

3. Fisher RS, Petty CS. Forensic pathology a handbook for pathologist. Castle house publication limited; 1980:123-28

4. J.B.Mukharjee's Forensic medicine and toxicology, violent asphyxia deaths, $4^{\text {th }}$ edition; Academic publication, Kolkata. 2011;499-538

5. Apurba Nandy, Principal of Forensic medicine including toxicology, $3^{\text {rd }}$ edition2010.p-517-539 
6. Parikh C.K. "Parikh's textbook of medical jurisprudence, Forensic Medicine and Toxicology for classrooms and courtrooms". $6^{\text {th }}$ edition,CBS publishers and distributors, New Delhi;; 2008. p.3.40-3.73

7. Polson CJ, Gee DJ, Knight B. Hanging and strangulation. In: The essential of Forensic Medicine, $4^{\text {th }}$ ed. Pergamon Press 1985;375-405.

8. Modi's Medical Jurisprudence \& Toxicology, $22^{\text {nd }}$ edition, Butterworths India, New Deihi.1999.p. 251-280.

9. Gordon I, Shapiro HA, Taljaard JJ, Engelbrecht HE. Arch Kriminol. 1999 May-Jun; 203(5-6):175-83

10. Pillay VV. Text book of Forensic Medicine and Toxicology; $14^{\text {th }}$ edition, 2004: 223-232.

11. Narayan Reddy KS. The Essentials of Forensic Medicine and Toxicology. 32 ${ }^{\text {th }}$ edition. Hyderabad;2013:3322-347

12. Ahmad M, Hossain M Z. Hanging as a Method of Suicide: Retrospective Analysis of Postmortem Cases. JAFMC Bangladesh 2010;6(2):37-9.

13. Shaikh MMM, H. J. Chotaliya, A.D. Modi, A. P. Parmar, D. Kalele. Study of Gross Postmortem Findings in Cases of Hanging and Ligature Strangulation by. J Indian Acad Forensic Med 2013;35(1).

14. Charoonnate N, Narongchai P, Vongvaivet S. Fractures of the Hyoid Bone and Thyroid Cartilage in Suicidal Hanging. J Med Assoc Thai 2010;93(10):1211-6.

15. Feigin G. Frequency of neck organ fractures in hanging. Am J Forensic Med Pathol 1999;20(2):128-30

16. Sharma BR, Harish D, Sharma S, Singh H. Injuries to neck structures in death due to constriction of neck, with a special reference to hanging. J Forensic Leg Med 2008;15:298-305.
17. Green H, James RA, Gilbert JD, Byard RW. Fractures of the hyoid bone and laryngeal cartilages in suicidal hanging. J Clin Forensic Med 2000;7(3):123-6.

18. Momin S G, Mangal H M; H.C. Kyada H C; Vijapura M T; Bhuva S D, Pattern of Ligature Mark in Cases of Compressed Neck in Rajkot Region: A Prospective Study, J Indian Acad Forensic Med 2012;34(1).

19. Naik SK, Patil DY. Fracture of hyoid bone in cases of asphyxial deaths resulting from constricting force round the neck. JIAFM 2005;27(3):149-53.

20. Chandrakanta M K, Bheemappa H, Devdass P K; Study of hyoid bone \& thyroid cartilage in hanging \& ligature strangulation; medico-legal update, Jan.-June 2015;15(1).

21. T.Saisudheer, T.V.Nagaraja. A study of ligature mark in cases of hanging deaths. Int J Pharm Biomed Sci 2012;3(3):80-4.

22. Rajs J, Thiblin I. Histological appearance of fractured thyroid cartilage and surrounding tissues. Forensic Sci Int 2000; 114(3):155-66.

23. Dr. M. I. Sheikh, Dr. S. S. Agarwal, Medicolegal Implications of Hyoid bone fracture - A study, JIAFM 2001;24(4):61-63.

How to cite this article: Kaushik V, Sheikh MI, Kaushik RV. Study of asphyxial death due to pressure over the neck with special reference to hyoid bone fracture, gross and radiological observations. Int $J$ Forensic Med Toxicol Sci 2019;4(3):86-91. 